\title{
Autonomic Regulation of the Goldfish Intact Heart
}

\begin{abstract}
Maedeh Bazmi ${ }^{1}$ and Ariel L. Escobar ${ }^{2 *}$
${ }^{1}$ Quantitative Systems Biology Program, School of Natural Sciences, University of California, Merced, Merced, CA, United States, ${ }^{2}$ Department of Bioengineering, School of Engineering, University of California, Merced, Merced, CA, United States
\end{abstract}

Autonomic regulation plays a central role in cardiac contractility and excitability in numerous vertebrate species. However, the role of autonomic regulation is less understood in fish physiology. Here, we used Goldfish as a model to explore the role of autonomic regulation. A transmural electrocardiogram recording showed perfusion of the Goldfish heart with isoproterenol increased the spontaneous heart rate, while perfusion with carbamylcholine decreased the spontaneous heart rate. Cardiac action potentials obtained via sharp microelectrodes exhibited the same modifications of the spontaneous heart rate in response to isoproterenol and carbamylcholine. Interestingly, the duration of the cardiac action potentials lengthened in the presence of both isoproterenol and carbamylcholine. To evaluate cardiac contractility, the Goldfish heart was perfused with the $\mathrm{Ca}^{2+}$ indicator Rhod-2 and ventricular epicardial $\mathrm{Ca}^{2+}$ transients were measured using Pulsed Local Field Fluorescence Microscopy. Following isoproterenol perfusion, the amplitude of the $\mathrm{Ca}^{2+}$ transient significantly increased, the half duration of the $\mathrm{Ca}^{2+}$ transient shortened, and there was an observable increase in the velocity of the rise time and fall time of the $\mathrm{Ca}^{2+}$ transient, all of which are compatible with the shortening of the action potential induced by isoproterenol perfusion. On the other hand, carbamylcholine perfusion significantly reduced the amplitude of the $\mathrm{Ca}^{2+}$ transient and increased the half duration of the $\mathrm{Ca}^{2+}$ transient. These results are interesting because the effect of carbamylcholine is opposite to what happens in classically used models, such as mouse hearts, and the autonomic regulation of the Goldfish heart is strikingly similar to what has been observed in larger mammalian models resembling humans.

\footnotetext{
Keywords: electrocardiogram, local field fluorescence microscopy, intracellular microelectrodes, sympathetic regulation, parasympathetic regulation
}

\section{INTRODUCTION}

In nearly all vertebrate species, direct input from the autonomic nervous system tightly controls cardiac contractility and excitability (Lee and Shideman, 1959; Katz, 1967; Lindemann and Watanabe, 1985; Cohn, 1989; Henning, 1992). Although there is an abundant amount of research on the autonomic control of cardiac contractility and excitability in numerous mammalian species, the characterization of pathophysiological mechanisms is still difficult to obtain for humans specifically. This is in part due to humans having strikingly dissimilar action potential (AP) characteristics and electrocardiographic morphology in comparison with commonly used animal 
models such as mice, rats, and rabbits (Nakamura et al., 2002; Tsai et al., 2011; Bazmi and Escobar, 2020). Fish, on the other hand, are the largest and most diverse group of vertebrates, and as such, their autonomic nervous system regulation can often deviate from the classical vertebrate models used to study autonomic control of cardiac contractility and excitability. The most drastic difference in autonomic system regulation can be observed when comparing the hagfish, which have no known autonomic nervous system control, to the teleost, which exhibit fully functional autonomic regulation in cardiac function (Sandblom and Axelsson, 2011). Nevertheless, if a fish species does exhibit autonomic regulation, it is likely to be similar to what has been established for many mammalian species.

In vertebrate species exhibiting full autonomic control, the autonomic nervous system functions through two closely intertwined antagonistic branches: the sympathetic branch and the parasympathetic branch. The sympathetic branch of the nervous system, referred to as the sympathetic nervous system, modulates cardiac function through the release of transmitters referred to as catecholamines (Lee and Shideman, 1959; Evans, 1986; Marks, 2013). These catecholamines bind to and stimulate $\beta$-adrenergic receptors, which in turn, increase the speed of conduction through the atrioventricular node (positive dromotropic effect), increase heart rate (positive chronotropic effect), increase contractility (positive inotropic effect), and increase the velocity of myocardial relaxation during diastole (positive lusitropic effect). Locally released catecholamines, such as norepinephrine (NE), stimulate the $\beta$-adrenergic receptors by activating adenylyl cyclase (AC; Hildebrandt et al., 1983; Brum et al., 1984) and increasing cyclic adenosine monophosphate (cAMP) levels (Osterrieder et al., 1982). Increased cAMP levels activate protein kinase A (PKA; Krebs, 1972; Hayes and Mayer, 1981) and induce the dissociation of the catalytic subunit. Levels of cAMP and thus PKA are finely regulated by cyclic nucleotide phosphodiesterases (PDEs) which degrade cAMP into $5^{\prime}$-AMP. Nevertheless, the catalytic subunit of PKA phosphorylates several key $\mathrm{Ca}^{2+}$ handling proteins such as the L-type $\mathrm{Ca}^{2+}$ Channel (LTCC; Collins et al., 1981; Osterrieder et al., 1982), the ryanodine receptor 2 (Suko et al., 1993; Valdivia et al., 1995), and phospholamban (PLN; Weilenmann et al., 1987). These modifications not only alter the electrical activity of the myocardium, which have positive dromotropic and chronotropic effects, but also $\mathrm{Ca}^{2+}$ handling dynamics in the myocardium which lead to positive inotropic and lusitropic effects (Aguilar-Sanchez et al., 2019).

The sympathetic branch of the nervous system is highly antagonized by the parasympathetic branch. Referred to as the parasympathetic nervous system, this branch modulates cardiac contractility and excitability through the local release of the transmitter acetylcholine $(\mathrm{ACh})$ from postganglionic cholinergic intracardiac neurons. The ACh subsequently binds to and stimulates muscarinic (M2) receptors. Activation of M2 receptors stimulates a $G_{i}$ protein, which inhibits AC (Krebs, 1972). This inhibition leads to significantly lower levels of cAMP, a reduced fraction of activated PKA, and a decreased degree of phosphorylation in the key $\mathrm{Ca}^{2+}$ handling proteins. These modifications result in negative inotropic, chronotropic, dromotropic, and lusitropic effects, all of which are crucial in countering the sympathetic nervous system and maintaining homeostasis in the vertebrate central nervous system (Watanabe and Lindemann, 1984; Aguilar-Sanchez et al., 2019).

Although fish hearts contain a single atrium and ventricle and present a fundamentally different cardiovascular system when compared to other mammalian models, there are many developmental, structural, and functional commonalities between the two vertebrate species (Sandblom and Axelsson, 2011; Mersereau et al., 2015; Xing et al., 2017; Bazmi and Escobar, 2020). The Goldfish specifically, has remarkably similar electrical properties to humans. For example, the heart rate, AP morphology, and $\mathrm{Ca}^{2+}$ transient kinetics and dynamics of adult Goldfish closely parallel those of humans, even more so than mice and Zebrafish models (Bazmi and Escobar, 2020).

Previous literature suggests few fish models exhibit autonomic control in a similar manner to larger mammals; however, it is not clear how autonomically driven AP kinetics impact cardiac contractility in the fish intact heart specifically. To explore how stimulation of either autonomic nervous system branch would alter cardiac contractility and excitability, we performed experiments in which we perfused the Goldfish intact heart with either a sympathetic or parasympathetic agonist. Ventricular APs, electrocardiograms, and $\mathrm{Ca}^{2+}$ transients recorded from the Goldfish intact heart showed perfusion with either $100 \mathrm{~nm}$ isoproterenol (sympathetic agonist) or $5 \mu \mathrm{m}$ carbamylcholine (parasympathetic agonist), was enough to stimulate the sympathetic branch or parasympathetic branch, respectively. Interestingly, our results indicate stimulation of the Goldfish autonomic nervous system by these commonly used agonists resulted in a corresponding change in cardiac dromotropism, chronotropism, inotropism, and lusitropism in a similar manner observed in humans.

\section{MATERIALS AND METHODS}

\section{Ethical Approval}

Our animal facilities are Association for Assessment and Accreditation of Laboratory Animal Care accredited and Office of Laboratory Animal Welfare certified and fully comply with all regulations, policies, and standards that protect animal welfare. Animal use in our studies were in accordance with the National Institutes of Health Guide for the Care and Use of Laboratory Animals (NIH Publication No. 85-23, Revised 1996) and the Institutional Animal Care and Use Committee guidelines of the University of California Merced (Protocol \# 2008-201). The animals were bought from Toledo Goldfish, United States.

Adult Goldfish were anesthetized by immersion in ice-cold water containing $0.16 \mathrm{mg} \mathrm{m}^{-1}$ tricaine methanesulfonate for 2-5 min. To assure the Goldfish were completely anesthetized prior to decapitation, the tail was held with a small, curved tweezer, and gently moved. Once the Goldfish were completely anesthetized, they were decapitated, and the intact heart was removed from the chest cavity.

\section{Heart Cannulation and Perfusion}

Goldfish hearts were dissected, and the bulbous arteriosus was cannulated onto a gauge 27 needle and perfused in a Langendorff system at a rate of $60 \mu \mathrm{l} / \mathrm{min}$ driven by gravity. Multiple solutions 
were perfused through the bulbus arteriosus with the aid of a self-designed $\mu$-manifold. Goldfish hearts were perfused with a fish ringer solution containing: $\mathrm{NaCl} 137 \mathrm{~mm}, \mathrm{KCl} 5.4 \mathrm{~mm}$, $\mathrm{CaCl}_{2} 1.8 \mathrm{~mm}, \mathrm{MgCl}_{2} 0.5 \mathrm{~mm}$, HEPES $10 \mathrm{~mm}$, and glucose $5.5 \mathrm{~mm}$. The $\mathrm{Ca}^{2+}$ dye Rhod-2 AM was perfused into the heart with a Harvard pump for $30-45 \mathrm{~min}$. The temperature of the bath containing the heart was set to $28^{\circ} \mathrm{C}$. The temperature was controlled with the aid of a Peltier unit positioned at the bottom of the recording chamber and measured with a linearized semiconductor temperature sensor.

\section{Pharmacological Agents}

The Goldfish heart was perfused with fish ringer solution containing $4 \mathrm{~mm}$ blebbistatin, prior to obtaining any electrophysiological recordings to suppress cardiac motion. In order to elicit a sympathetic response, the Goldfish heart was perfused with fish ringer solution containing $100 \mathrm{~nm}$ isoproterenol for $10 \mathrm{~min}$ before the start of any $\mathrm{AP}$ and $\mathrm{Ca}^{2+}$ transient recordings. To determine if the sympathetic response to isoproterenol could be reversed, the Goldfish heart was perfused with fish ringer solution for a prolonged amount of time. Indeed, the effects of isoproterenol could be completely reversed if the Goldfish heart were continuously perfused with fish ringer solution for $20 \mathrm{~min}$. In contrast, to elicit a parasympathetic response the Goldfish heart was perfused with fish ringer solution containing $5 \mu \mathrm{m}$ carbamylcholine for $10 \mathrm{~min}$ prior to the start of any $\mathrm{AP}$ and $\mathrm{Ca}^{2+}$ transient recording. The effects of carbamylcholine could be completely reversed after continuously perfusing the heart with fish ringer solution for $60 \mathrm{~min}$. Recordings obtained prior to perfusion with isoproterenol or carbamylcholine were considered as control, and recordings obtained following isoproterenol or carbamylcholine perfusion were considered as experimental.

\section{Experimental Setup Optical Measurements}

$\mathrm{Ca}^{2+}$ transients were recorded $(N=8$ hearts) using Pulsed Local Field Fluorescence Microscopy (PLFFM; Mejía-Alvarez et al., 2003; Escobar et al., 2004, 2006; Valverde et al., 2006, 2010; Kornyeyev et al., 2010; Mattiazzi et al., 2015; AguilarSanchez et al., 2017). The PLFFM technique assessed physiological parameters by exciting exogenous probes present in the tissue and detecting the light emitted by these fluorescent indicators. The excitation (532 nm Yag laser) and emitted light propagated through a multimode fiber optic ( $200 \mathrm{~mm}$ diameter, $0.67 \mathrm{NA}$ ) placed on the surface of the intact heart. The emitted light then traveled back through the multimode fiber, dichroic mirrors, and filters $(610 \mathrm{~nm})$ and was focused on an avalanche photodiode (Perkin Elmer, United States) with the aid of a microscope objective. The signal was digitized by an A/D converter (NI, United States) and acquired by a PC. The fluorescent indicator utilized to obtain $\mathrm{Ca}^{2+}$ transients in this study was Rhod-2 AM. Often referred to as a " $\mathrm{Ca}^{2+}$ indicator dye," Rhod-2 AM $(50 \mu \mathrm{g})$ was prepared with $20 \mu \mathrm{l}$ of $20 \%$ pluronic in $1 \mathrm{ml}$ fish ringer solution.

\section{Electrophysiological Measurements}

Epicardial electrical recordings of the APs ( $N=4$ hearts) were obtained using sharp glass microelectrodes filled with $3 \mathrm{M} \mathrm{KCl}$ connected to a high input impedance differential amplifier (WPI, United States). Glass microelectrodes were fabricated with a micropipette puller (Sutter Instrument Co., United States) and had a resistance of 10-20 M $\Omega$ (Ferreiro et al., 2012; López Alarcón et al., 2019). Data were recorded with an acquisition system from National Instruments in conjunction with additional software built in our lab. All fluorescence and membrane potential recordings were obtained from the Goldfish ventricular epicardium. Goldfish hearts were continuously paced at $1 \mathrm{~Hz}$ with the aid of two acupuncture needles placed in the apex of the ventricle in the presence and absence of the pharmacological agents. However, the hearts were not paced in experiments assessing changes in the spontaneous heart rate.

\section{Whole Heart Electrocardiographic Measurements}

Transmural electrocardiographic recordings ( $N=6$ hearts) were performed by placing one $\mathrm{Ag}-\mathrm{AgCl}$ micropellet inside the left ventricle and a second pellet outside the left ventricle (Kornyeyev et al., 2010; López Alarcón et al., 2019). Signals were amplified by a custom-made DC-coupled instrumentation amplifier and were digitally sampled identically to the AP recordings.

\section{Statistical Analysis}

In whole heart experiments, there are two main causes of variance. First, no two animals have entirely identical hearts, regardless of the species. Second, although we are measuring $\mathrm{Ca}^{2+}$ transients and APs in the same region (the mid-region of the left ventricle) of the heart, it is impossible to perform the recordings in the same precise location between different hearts. Thus, the data are presented as the measured times with their standard error (SEM). To assess electrical changes, AP traces were first normalized then evaluated at their respective repolarization times. Specifically, the time it takes for the AP to reach $30,50 \%$, or $90 \%$ repolarization, referred to here as APD30, APD50, or APD90, respectively.

Each wave of the electrocardiogram (QRS complex, T wave, and J wave) was measured using its corresponding half duration. The recorded $\mathrm{Ca}^{2+}$ transients were normalized between zero (minimum fluorescence) and one (maximum fluorescence) in order to evaluate the kinetics of the recorded $\mathrm{Ca}^{2+}$ transients. The kinetic parameters of the $\mathrm{Ca}^{2+}$ transients evaluated were the rise time (time for the $\mathrm{Ca}^{2+}$ transient to rise from, 10 to $90 \%$ of its maximum amplitude), half duration (duration of the $\mathrm{Ca}^{2+}$ transient at $50 \%$ of the maximum amplitude), and fall time (time for the $\mathrm{Ca}^{2+}$ transient to fall from 90 to $10 \%$ of the maximum amplitude). The AP parameters and $\mathrm{Ca}^{2+}$ transient kinetics obtained for the control and the experimental groups were evaluated and normalized to their respective control values for each heart used. After this normalization, data were compiled, and statistical analysis was performed.

The data are presented as multiple measurements ( $n$; dot cloud) recorded for different measurements $(n)$ on different hearts $(N)$ with the mean \pm SEM (solid lines). To determine 
if the agonists produced a significant effect, the distribution of the data before and after administration was compared using a two-sample Kolmogorov-Smirnov test (OriginPro, 2019). The difference was significant if the value of $p<0.01$.

\section{RESULTS}

\section{Sympathetic Regulation of Action Potentials and Heart Rate}

In order to elicit a sympathetic response and assess the $\beta$-adrenergic regulation of the Goldfish heart, we first perfused the heart with $100 \mathrm{~nm}$ isoproterenol. Goldfish ventricular chronotropic properties were examined via AP recordings and spontaneous heart rate recordings (Figure 1). Perfusion of the Goldfish intact heart with $100 \mathrm{~nm}$ isoproterenol altered the AP morphology (Figure 1A) and had a positive chronotropic effect, significantly increasing the heart rate by $46 \%$ (Figures 1B,C; from $0.87 \pm 0.01 \mathrm{~Hz}$ to $1.27 \pm 0.02 \mathrm{~Hz}$ ). Interestingly, all kinetic parameters of the AP significantly changed following isoproterenol perfusion; APD30 increased from $228.10 \pm 14.40 \mathrm{~ms}$ to $237.90 \pm 11.80 \mathrm{~ms}$ (Figure 2A), APD50 decreased from $353.90 \pm 30.40 \mathrm{~ms}$ to $300.30 \pm 20.00 \mathrm{~ms}$ (Figure 2B), and APD90 increased from $455.40 \pm 20.10 \mathrm{~ms}$ to $468.70 \pm 27.00 \mathrm{~ms}$ (Figure 2C).

\section{Sympathetic Prevalence in Electrocardiographic Signals}

The effects of catecholamines on whole heart electrical activity were assessed through transmural electrocardiogram recordings (Figure 3). The 3 main components of the Goldfish electrocardiogram are presented in Figure $\mathbf{3 A}$ and consist of the QRS complex (ventricular depolarization), J wave (likely due to a voltage gradient due to the presence of a prominent AP notch in the epicardium but not the endocardium), ending with $\mathrm{T}$ wave (ventricular repolarization).
Application of isoproterenol altered the morphology of the Goldfish electrocardiogram (Figure 3A) and increased the heart rate (Figures 3B,C; from $1.10 \pm 0.40 \mathrm{~Hz}$ to $3.10 \pm 0.70 \mathrm{~Hz}$ ). Furthermore, application of isoproterenol also significantly altered the duration of the QRS wave, $\mathrm{T}$ wave, and $\mathrm{J}$ wave (Figure 4). The QRS complex significantly decreased from $22.70 \pm 1.30 \mathrm{~ms}$ to $17.30 \pm 2.80 \mathrm{~ms}$ (Figure $4 \mathbf{A}$ ), the $\mathrm{T}$ wave significantly increased from $164.70 \pm 53.20 \mathrm{~ms}$ to $292.10 \pm 58.10 \mathrm{~ms}$ (Figure 4B), the $\mathrm{J}$ wave significantly increased from $126.10 \pm 42.30 \mathrm{~ms}$ to $333.10 \pm 105.30 \mathrm{~ms}$ (Figure 4C).

\section{Sympathetic Regulation of Cardiac Contractility}

In many vertebrate species, stimulation of either autonomic nervous system branch will not only alter cardiac excitability, but also cardiac contractility. In order to assess if eliciting a sympathetic response altered the inotropic and/or the lusitropic properties of the Goldfish ventricle, experiments were performed in which the amplitude and kinetics of the $\mathrm{Ca}^{2+}$ transient were examined in the presence and absence of $100 \mathrm{~nm}$ isoproterenol (Figure 5). Stimulation of $\beta$-adrenergic receptors altered the morphology of the $\mathrm{Ca}^{2+}$ transient (Figure 5A) and significantly increased the normalized amplitude of the $\mathrm{Ca}^{2+}$ transient (Figure 5B; from $1.00 \pm 0.07$ to $1.10 \pm 0.04)$. To detect if isoproterenol significantly altered the kinetics of the $\mathrm{Ca}^{2+}$ transient, the three following parameters of the $\mathrm{Ca}^{2+}$ transient were assessed (Figure 6): rise time (RT), fall time (FT), and half duration (HD). A significant change in any aforementioned kinetical parameter is a reflection of a significant corresponding change in myocardial $\mathrm{Ca}^{2+}$ handling dynamics. Perfusion of isoproterenol significantly increased the velocity of every $\mathrm{Ca}^{2+}$ transient kinetic parameter in the Goldfish heart (Figures 6A-C; RT: from $27.98 \pm 4.60 \mathrm{~ms}$ to $22.47 \pm 3.50 \mathrm{~ms}$, FT: from $150.08 \pm 22.80 \mathrm{~ms}$ to $135.88 \pm 20.30 \mathrm{~ms}$, and $\mathrm{HD}$ : from $148.60 \pm 8.10 \mathrm{~ms}$ to $134.87 \pm 5.20 \mathrm{~ms}$ ), implying

\section{A}

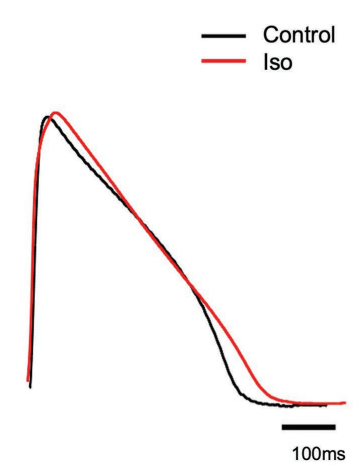

\section{B}

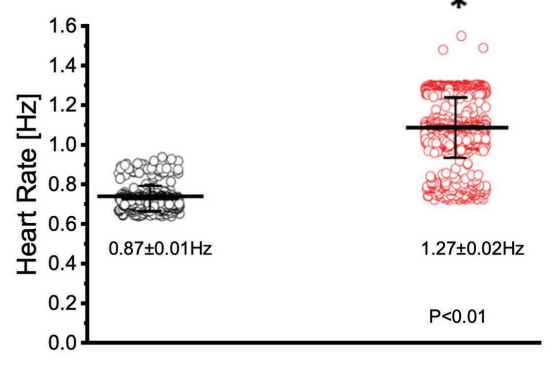

C

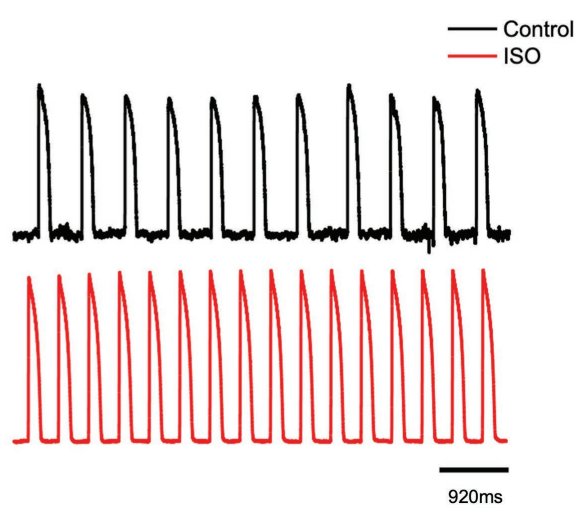

FIGURE 1 | Goldfish ventricular action potential and spontaneous heart rate recordings before (black) and after perfusion with 100 nm isoproterenol (red). Perfusion of the Goldfish intact heart with $100 \mathrm{~nm}$ isoproterenol altered the action potential morphology (A) and had a positive chronotropic effect, significantly increasing the heart rate $(\mathbf{B}$; from $0.87 \pm 0.01 \mathrm{~Hz}$ to $1.27 \pm 0.02 \mathrm{~Hz}, p<0.01, n=160$ for the control, $n=263$ for ISO, $N=4)$. The positive chronotropic effect following isoproterenol perfusion is also reflected in spontaneous AP recordings from the left ventricle (C). *Denotes a significant difference between the two distributions. The data are presented as multiple measurements ( $n$; dot cloud) recorded for different measurements $(n)$ on different hearts ( $N$ ) with the mean \pm SEM (solid lines). 

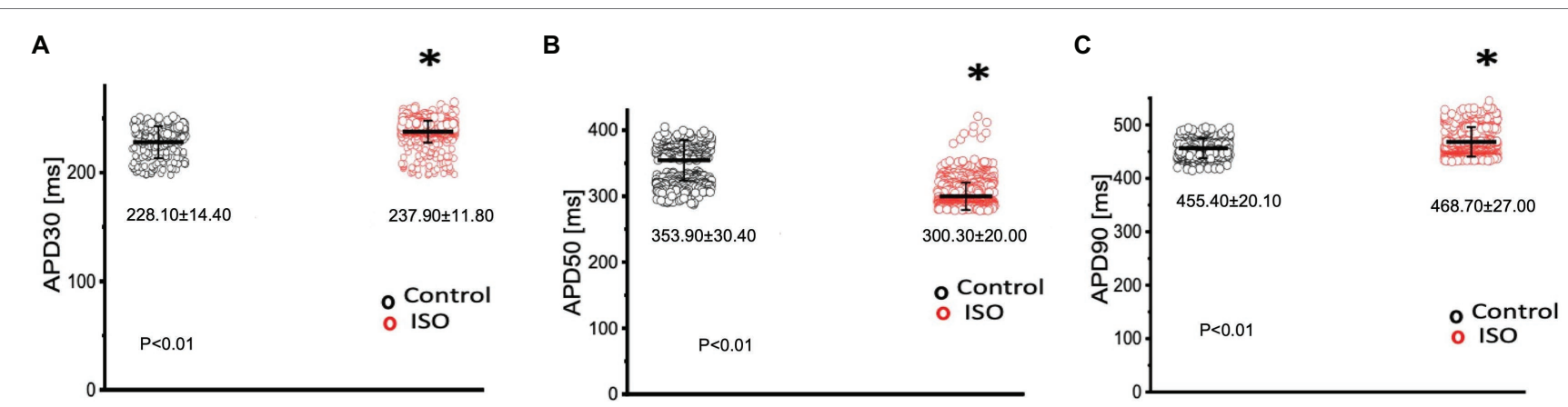

FIGURE 2 | Kinetic parameters of the Goldfish ventricular action potential before (black) and after (red) perfusion with $100 \mathrm{~nm}$ isoproterenol. Following isoproterenol perfusion, APD30s significantly increased from $228.10 \pm 14.40 \mathrm{~ms}$ to $237.90 \pm 11.80 \mathrm{~ms}(p<0.01, n=113$ for the control, $n=113$ for ISO, N=4; A), APD50 decreased from $353.90 \pm 30.40 \mathrm{~ms}$ to $300.30 \pm 20.00 \mathrm{~ms}(p<0.01, n=143$ for the control, $n=316$ for ISO, $N=4$; B), and APD90 significantly increased from $455.40 \pm 20.10 \mathrm{~ms}$ to $468.70 \pm 27.00 \mathrm{~ms}(p<0.01, n=95$ for the control, $n=256$ for ISO, $N=4$; C). *Denotes a significant difference between the two distributions. The data are presented as multiple measurements ( $n$; dot cloud) recorded for different measurements $(n)$ on different hearts $(N)$ with the mean \pm SEM (solid lines).

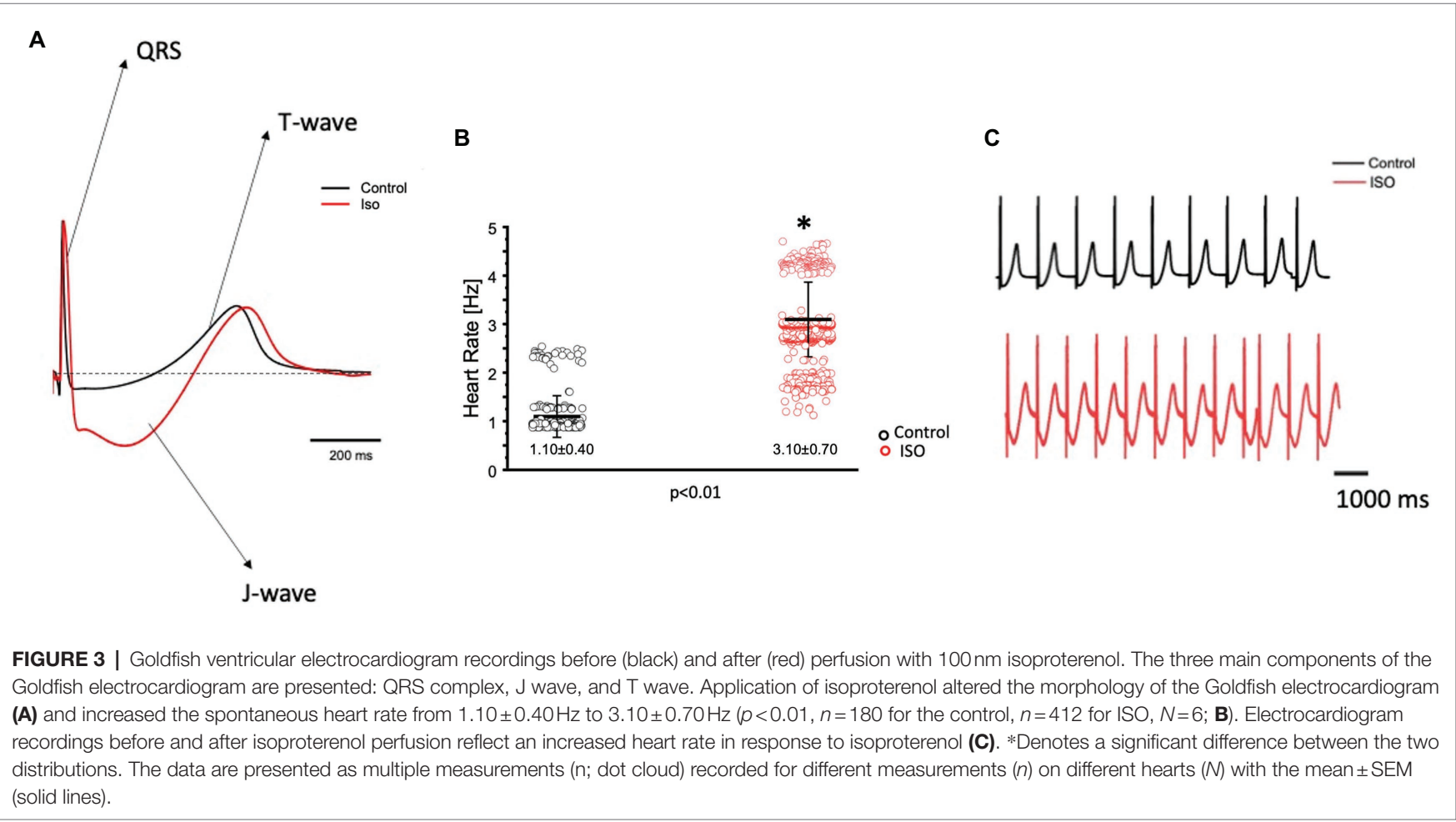

perfusion with isoproterenol increased the rate of relaxation of the Goldfish myocardium during diastole, resulting in a positive lusitropic effect (Figure 6B). The presence of a $\beta$-adrenergic drive suggests the presence of a parasympathetic one, as they are the two antagonistic branches of the autonomic nervous system.

\section{Parasympathetic Regulation of Action Potentials and Heart Rate}

The parasympathetic nervous system, on the other hand, is thought to be the dominant branch of the autonomic nervous system. To elicit a parasympathetic response and induce a cholinergic response, $5 \mu \mathrm{m}$ carbamylcholine was administered to the Goldfish intact heart. As before, the chronotropic properties of the heart were assessed via AP and spontaneous heart rate recordings. Not surprisingly, the administration of carbamylcholine altered the AP morphology (Figure 7A) and had a negative chronotropic effect, reducing the heart rate by $92.2 \%$ (Figures 7B,C; from $0.98 \pm 0.05 \mathrm{~Hz}$ to $0.13 \pm 0.08 \mathrm{~Hz}$ ). Not surprisingly, carbamylcholine administration significantly prolonged all three kinetic parameters of the AP (Figures 8A-C; APD30 increased from $235.90 \pm 12.10 \mathrm{~ms}$ to $295.30 \pm 11.50 \mathrm{~ms}$, APD50 increased from $388.10 \pm 23.90 \mathrm{~ms}$ to $651.40 \pm 49.50 \mathrm{~ms}$, and APD90 increased from $446.70 \pm 14.60 \mathrm{~ms}$ to $833.60 \pm 30.00 \mathrm{~ms}$, respectively). 

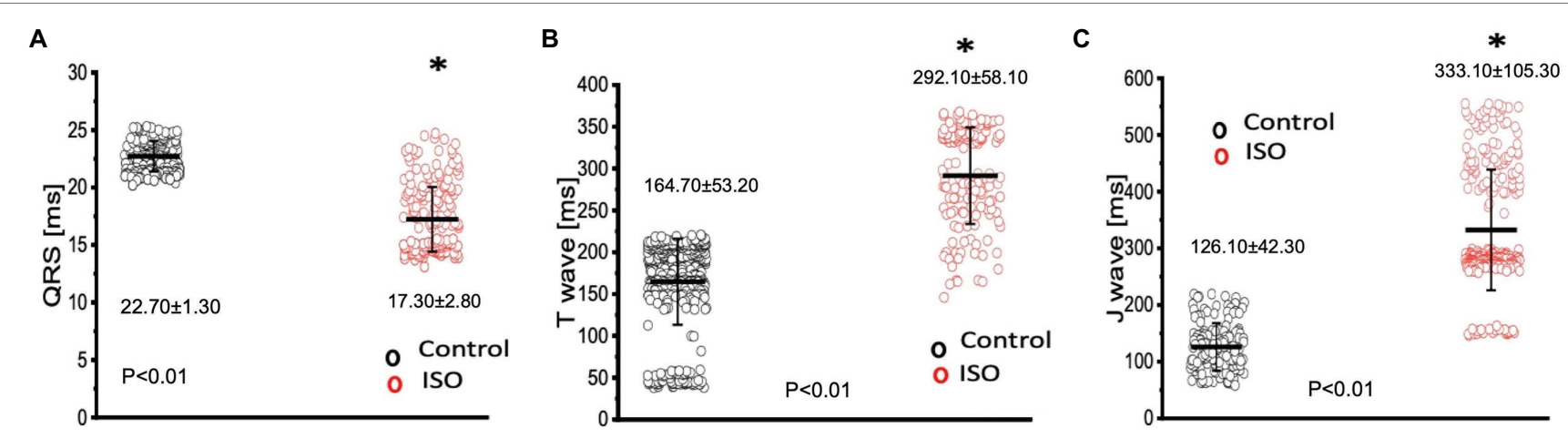

FIGURE 4 | Perfusion with $100 \mathrm{~nm}$ isoproterenol significantly altered the time course of all three components in the Goldfish electrocardiogram. The duration of the QRS complex significantly decreased from $22.70 \pm 1.30 \mathrm{~ms}$ to $17.30 \pm 2.80 \mathrm{~ms}(p<0.01, n=80$ for the control, $n=121$ for ISO, N=6; A), T wave significantly increased from $164.70 \pm 53.20 \mathrm{~ms}$ to $292.10 \pm 58.10 \mathrm{~ms}(p<0.01, n=110$ for the control, $n=120$ for ISO, $N=6$; B), and the $\mathrm{J}$ wave significantly increased from $126.10 \pm 42.30 \mathrm{~ms}$ to $333.10 \pm 105.30 \mathrm{~ms}(p<0.01, n=74$ for the control, $n=118$ for ISO, $N=6$; $\mathbf{C})$. *Denotes a significant difference between the two distributions. The data are presented as multiple measurements ( $n$; dot cloud) recorded for different measurements $(n)$ on different hearts $(M)$ with the mean \pm SEM (solid lines).

\section{A

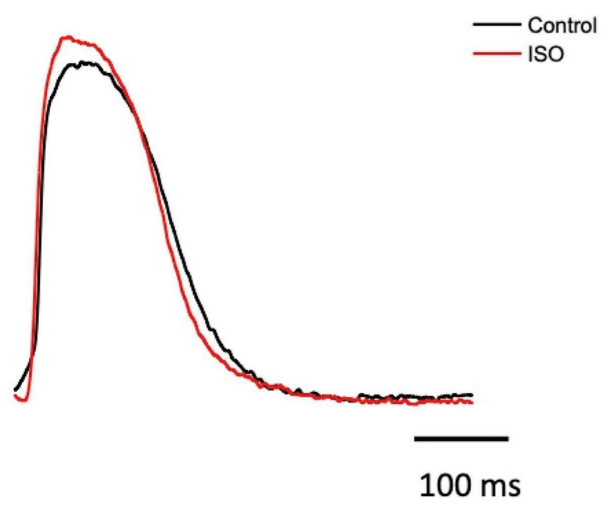 \\ Parasympathetic Prevalence in Electrocardiographic Signals}

B

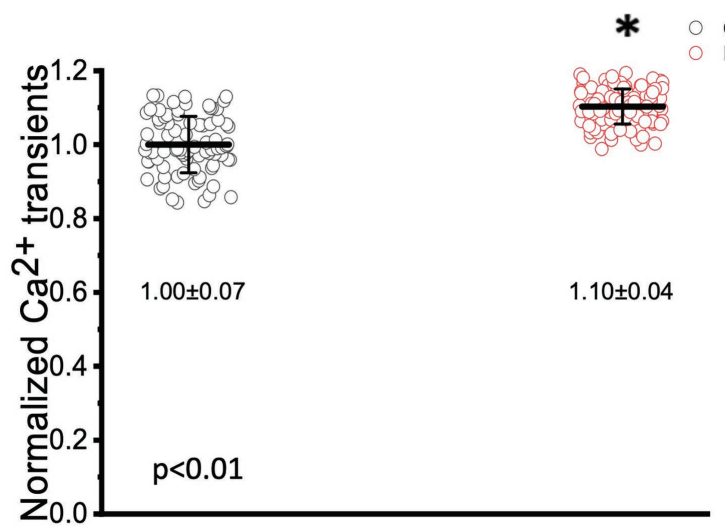

FIGURE 5 | Goldfish ventricular $\mathrm{Ca}^{2+}$ transient recording and normalized amplitude in the absence (black) and presence (red) of $100 \mathrm{~nm}$ isoproterenol. Stimulation of $\beta$-adrenergic receptors altered the morphology of the $\mathrm{Ca}^{2+}$ transient $\mathbf{( A )}$ and significantly increased the normalized amplitude of the $\mathrm{Ca}{ }^{2+}$ transient from $1.00 \pm 0.07$ to $1.10 \pm 0.04(p<0.01, n=65$ for the control, $n=67$ for ISO, $N=8$; B). *Denotes a significant difference between the two distributions. The data are presented as multiple measurements ( $n$; dot cloud) recorded for different measurements $(n)$ on different hearts $(N)$ with the mean \pm SEM (solid lines).

To further assess how cholinergic stimulation altered whole heart electrical activity in the Goldfish model, transmural electrocardiograms were recorded in the presence and absence of $5 \mu \mathrm{m}$ carbamylcholine (Figure 9). The morphology of the Goldfish electrocardiogram changed dramatically in response to cholinergic stimulation (Figure 9A) and significantly decreased the spontaneous heart rate (Figures 9B,C; from $1.00 \pm 0.04 \mathrm{~Hz}$ to $0.15 \pm 0.09 \mathrm{~Hz}$ ).

Cholinergic stimulation significantly altered the duration of the QRS complex, the $\mathrm{T}$ wave, and the $\mathrm{J}$ wave (Figure 10). The QRS complex significantly decreased from: $33.20 \pm 2.40 \mathrm{~ms}$ to $31.90 \pm 1.80 \mathrm{~ms}$ (Figure 10A), the T wave significantly increased from $370.20 \pm 3.70 \mathrm{~ms}$ to $379.70 \pm 14.40 \mathrm{~ms}$ (Figure 10B), and the J wave significantly increased from $169.20 \pm 30.20 \mathrm{~ms}$ to $326.60 \pm 23.30 \mathrm{~ms}$ (Figure 10C). The increased J wave duration is likely reflective of the decreased heart rate observed in Figures 7B, 9C.

\section{Parasympathetic Regulation of Cardiac Contractility}

In many vertebrate species, stimulation of either autonomic nervous system branch will not only alter cardiac excitability, but also cardiac contractility. To assess if stimulation of either autonomic nervous system branch altered the inotropic and/ or the lusitropic properties of the Goldfish ventricle, experiments were performed in which the amplitude and kinetics of the $\mathrm{Ca}^{2+}$ transient were examined in the presence and absence of a cholinergic agonist. 


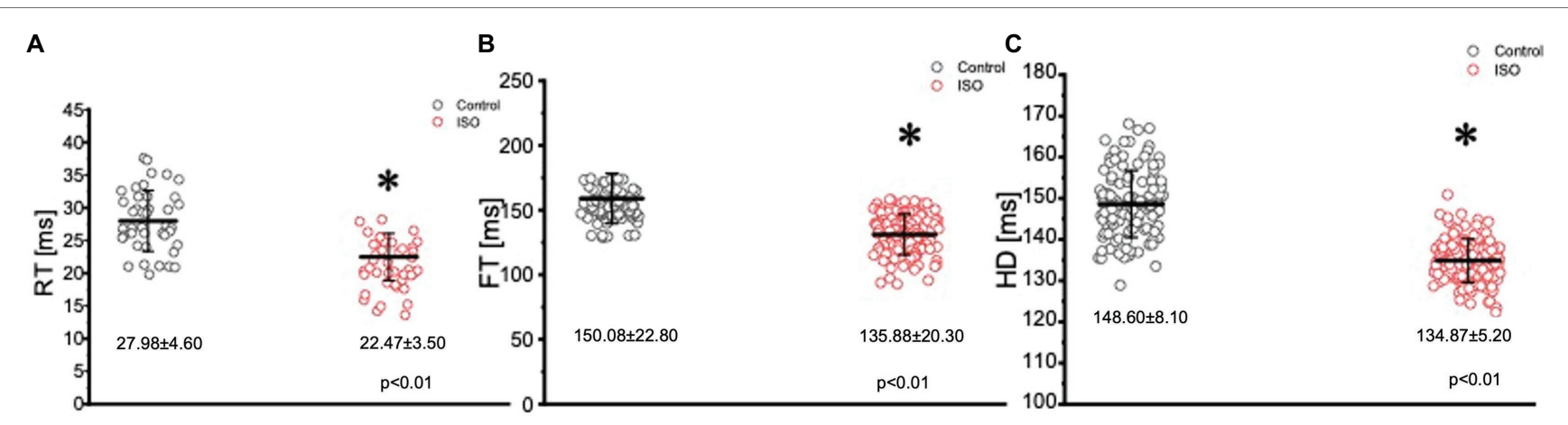

FIGURE 6 | Kinetic parameters of the Goldfish ventricular $\mathrm{Ca}^{2+}$ transients before (black) and after (red) perfusion with $100 \mathrm{~nm}$ isoproterenol. Perfusion of the Goldfish heart with $100 \mathrm{nM}$ isoproterenol significantly decreased the rise time (RT) of the $\mathrm{Ca}^{2+}$ transient from $27.98 \pm 4.60 \mathrm{~ms}$ to $22.47 \pm 3.50 \mathrm{~ms}(p<0.01, n=65$ for the control, $n=96$ for ISO, $N=8$; A), decreased the fall time ( $F T$ ) of the $\mathrm{Ca}^{2+}$ transient from $150.08 \pm 22.80 \mathrm{~ms}$ to $135.88 \pm 20.30 \mathrm{~ms}(p<0.01, n=76$ for the control, $n=76$ for ISO, $N=8$; B), and significantly decreased the half duration (HD) of the $\mathrm{Ca}^{2+}$ transient from $148.60 \pm 8.10 \mathrm{~ms}$ to $134.87 \pm 5.20 \mathrm{~ms}(p<0.01, n=64$ for the control, $n=72$ for ISO, $N=8$; C). *Denotes a significant difference between the two distributions. The data are presented as multiple measurements (n; dot cloud) recorded for different measurements $(n)$ on different hearts $(N)$ with the mean \pm SEM (solid lines).

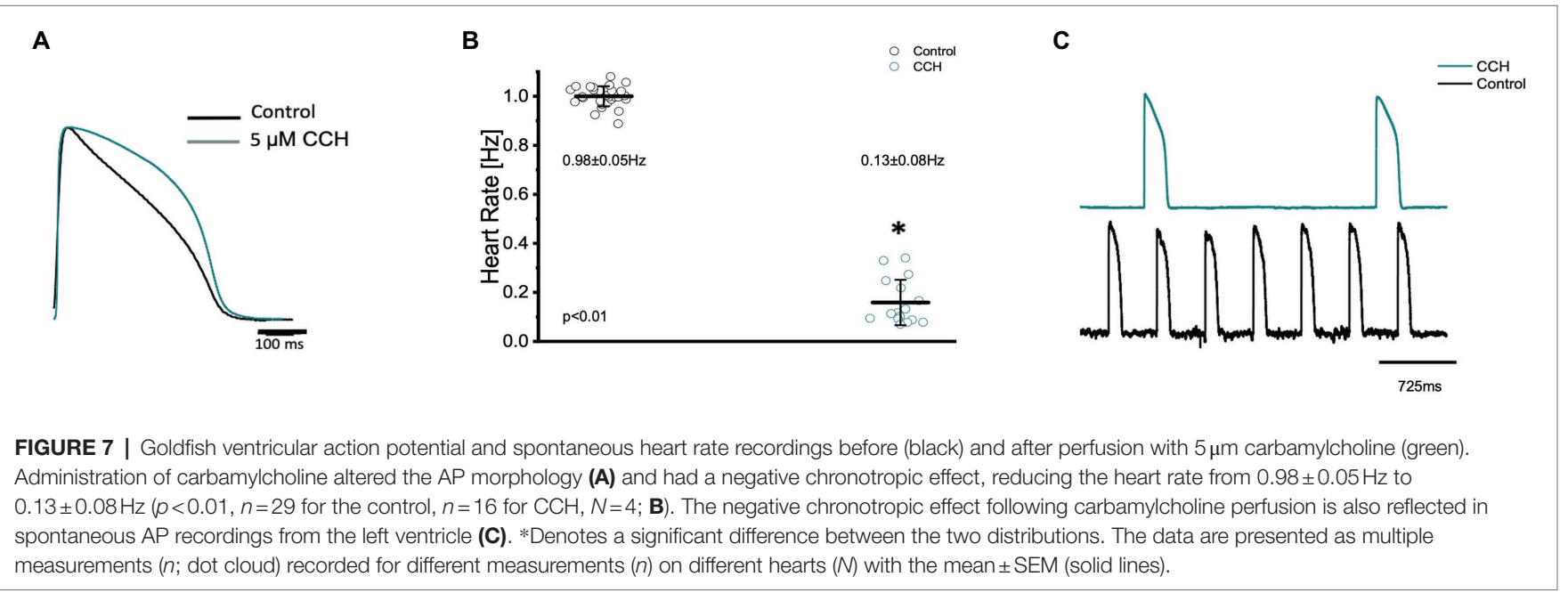

To assess cholinergic regulation of contractility specifically, $\mathrm{Ca}^{2+}$ transients were recorded from the epicardial wall of the Goldfish ventricle in the presence and absence of $5 \mu \mathrm{m}$ carbamylcholine (Figure 11). Administration of carbamylcholine had a negative inotropic effect, as the amplitude of the $\mathrm{Ca}^{2+}$ transient (Figure 11A) decreased in the presence of carbamylcholine. This negative inotropic effect is also presented in Figure 11B, where the normalized amplitude of the $\mathrm{Ca}^{2+}$ transient significantly decreased from $1.00 \pm 0.10$ to $0.49 \pm 0.03$ following cholinergic stimulation.

The three kinetical properties of the $\mathrm{Ca}^{2+}$ transient, including the rise time (RT), fall time (FT), and half duration (HD) were also evaluated to better understand how stimulation of the cholinergic pathway affected $\mathrm{Ca}^{2+}$ handling kinetics in the Goldfish myocardium (Figure 12). Although administration of $5 \mu \mathrm{m}$ carbamylcholine did not significantly increase the rise time of the $\mathrm{Ca}^{2+}$ transient (Figure 12A; $30.20 \pm 5.40 \mathrm{~ms}$ to $31.20 \pm 3.20 \mathrm{~ms}$ ), it did significantly increase the half duration of the $\mathrm{Ca}^{2+}$ transient (Figure 12C; from $151.80 \pm 2.30 \mathrm{~ms}$ to
$160.30 \pm 4.00 \mathrm{~ms})$. This effect can be due to the longer APs induced via cholinergic stimulation. Interestingly we were unable to observe a significant difference in the relaxation time (Figure 12B; from $161.50 \pm 15.10 \mathrm{~ms}$ to $150.70 \pm 12.10 \mathrm{~ms}$ ) of the $\mathrm{Ca}^{2+}$ transient. This suggests carbamylcholine application did not significantly modify the lusitropic property of the Goldfish myocardium in these experiments; however, a significant change in the half duration of the $\mathrm{Ca}^{2+}$ transient does indicate the presence of an intrinsic parasympathetic tone in the Goldfish isolated heart, capable of modifying $\mathrm{Ca}^{2+}$ transient kinetics.

\section{DISCUSSION}

In most vertebrate hearts, both excitability and contractility are tightly regulated by the autonomic nervous system. Though there is a significant amount of research regarding the sympathetic and parasympathetic regulation of many vertebrate species, there is little known about how autonomic regulation impacts the electrical 


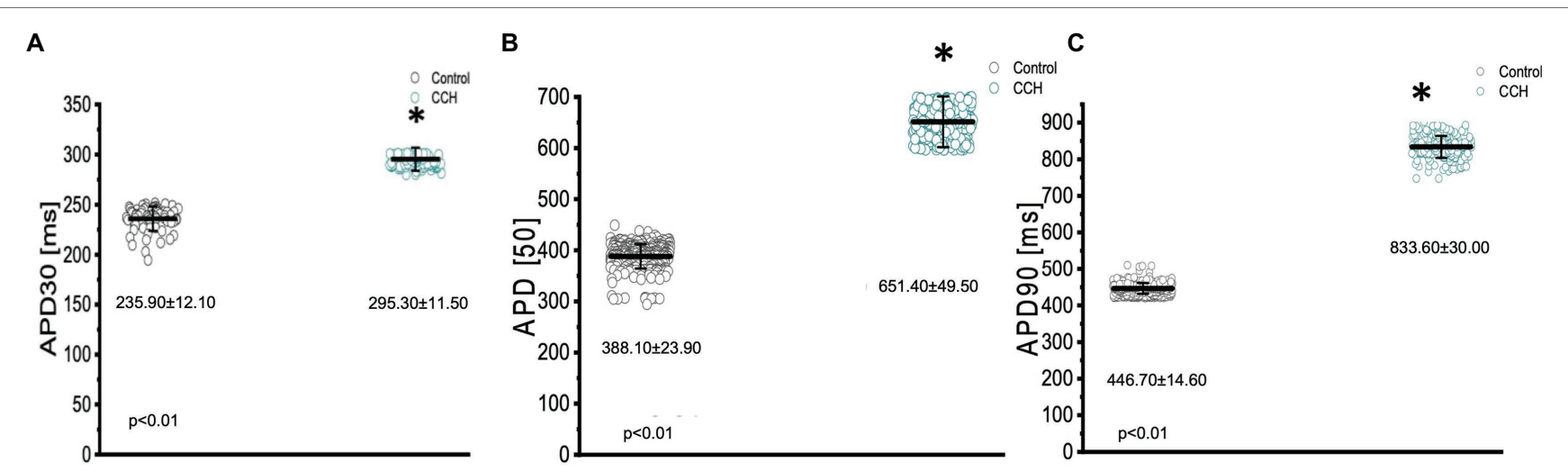

FIGURE 8 | Kinetic parameters of the Goldfish ventricular action potential before (black) and after (green) perfusion with $5 \mu$ m carbamylcholine. APD30 significantly increased from $235.90 \pm 12.10 \mathrm{~ms}$ to $295.30 \pm 11.50 \mathrm{~ms}(p<0.01, n=80$ for the control, $n=49$ for $\mathrm{CCH}, N=4$; A), APD50 significantly increased from $388.10 \pm 23.90 \mathrm{~ms}$ to $651.40 \pm 49.50 \mathrm{~ms}(p<0.01, n=379$ for the control, $n=308$ for $\mathrm{CCH}$. $N=4$; B), and APD90 significantly increased from $446.70 \pm 14.60 \mathrm{~ms}$ to $833.60 \pm 30.00 \mathrm{~ms}(p<0.01, n=455$ for the control, $n=201 \mathrm{for} \mathrm{CCH}, N=4 ; \mathbf{C})$. *Denotes a significant difference between the two distributions. The data are presented as multiple measurements ( $n$; dot cloud) recorded for different measurements $(n)$ on different hearts $(M)$ with the mean \pm SEM (solid lines).

FIGURE $\mathbf{9}$ I Transmural ventricular electrocardiogram recordings in the absence (black) and presence (green) of $5 \mu \mathrm{m}$ carbamylcholine. The three main components
of the Goldfish electrocardiogram are presented: QRS complex, J wave, and T wave (A). Carbamylcholine administration significantly altered the kinetic parameters
of all the electrocardiographic signals. Administration of carbamylcholine significantly decreased heart rate from $1.00 \pm 0.04 \mathrm{~Hz}$ to $0.15 \pm 0.09 \mathrm{~Hz}(p<0.01, n=29 \mathrm{for}$
the control, $n=16$ for CCH, $\mathrm{N}=6$; $\mathbf{B})$. Electrocardiogram recordings before and after carbamylcholine perfusion reflect a decreased heart rate in response to
carbamylcholine (C). *Denotes a significant difference between the two distributions. The data are presented as multiple measurements ( $(n$; dot cloud) recorded for
different measurements $(n)$ on different hearts $(\mathrm{N})$ with the mean \pm SEM (solid lines).

and mechanical function of fish hearts specifically. To our knowledge, it is not clear how autonomically driven AP kinetics impact contractility in the intact fish heart, which has become an increasingly popular model used to understand human cardiac physiology and pathophysiology. In this study, we investigated how stimulation of either autonomic branch regulated the time course of APs and electrocardiograms, and how these electrical changes correlated with changes in left ventricular $\mathrm{Ca}^{2+}$ transient measurements at the whole heart level. Our results indicate the presence of a fully developed dual control from both the adrenergic and cholinergic nerves in the Goldfish heart, highly resembling the pattern found in other vertebrate models.

\section{$\beta$-Adrenergic Stimulation Increased Cardiac Excitability and Contractility}

It is well-established stimulation of $\beta$-adrenergic receptors will have a positive chronotropic, dromotropic, inotropic, and lusitropic effect in any vertebrate species exhibiting full autonomic regulation. In the fish model, the autonomous rhythm of the heart is determined by the pacemaker region located near the atrial chamber, identified over 100 years ago (Keith and Mackenzie, 1910). Pacemaker APs are categorized by a gradual and slow diastolic depolarization (Phase 4), toward the threshold voltage of the AP upstroke (Phase 0; Saito, 1973; Harper et al., 1995; Haverinen and Vornanen, 2007; Tessadori et al., 2012). There are three main mechanisms by which an organism can modulate its heart rate, all of which end with an altered slope of the diastolic depolarization during diastole. This slope, set by the sinoatrial node, can be modified positively (by the sympathetic nervous system) or negatively (by the parasympathetic nervous system) by shifting the maximum diastolic potential, or decreasing the rate of depolarization, or (positively or negatively) shifting the membrane potential threshold; all of which could either increase or decrease 

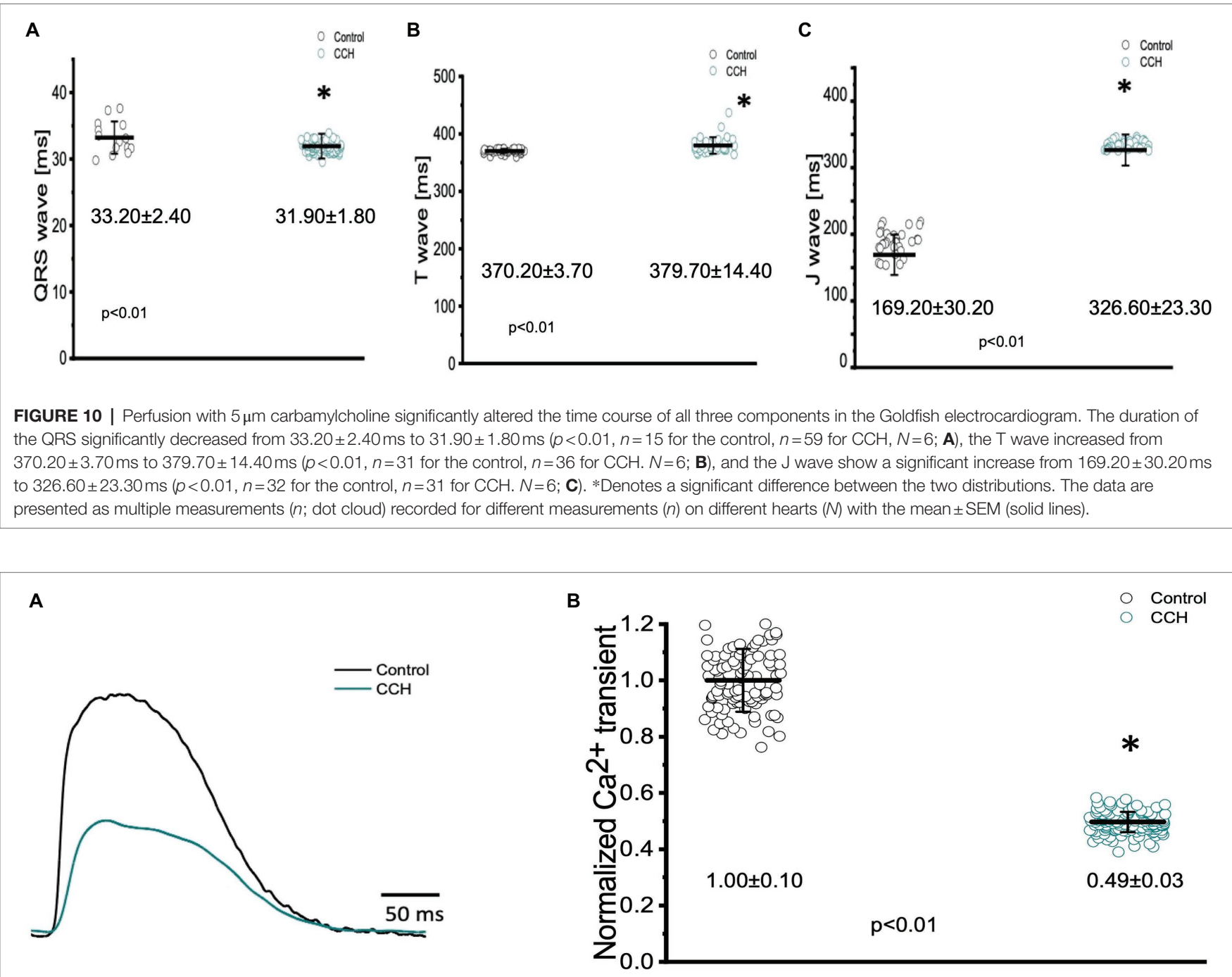

FIGURE 11 | Goldfish ventricular $\mathrm{Ca}^{2+}$ transient recording and normalized amplitude in the absence (black) and presence (green) of $5 \mu \mathrm{m}$ carbamylcholine. Perfusion with carbamylcholine altered the morphology of the $\mathrm{Ca}^{2+}$ transient $\mathbf{( A )}$ and significantly decreased the normalized amplitude of the $\mathrm{Ca}^{2+}$ from $1.00 \pm 0.10$ to $0.49 \pm 0.03(p<0.01, n=108$ for the control, $n=143$ for $\mathrm{CCH}, N=8$; B). *Denotes a significant difference between the two distributions. The data are presented as multiple measurements ( $n$; dot cloud) recorded for different measurements $(n)$ on different hearts $(N)$ with the mean \pm SEM (solid lines).

the time required for the membrane potential to reach the threshold and fire an AP. In the Goldfish model, administration of isoproterenol altered ventricular AP morphology and had a positive chronotropic effect (Figures 1A-C). Remarkably, previous studies have observed isoproterenol to induce strikingly similar AP morphological changes in canine endocardial myocytes and guinea pig cardiomyocytes (O'Hara and Rudy, 2012; Szentandrássy et al., 2012; Sala et al., 2018).

The changes in the AP morphology can be better observed in Figure 2, where the kinetics of the ventricular AP are presented following adrenergic stimulation with isoproterenol. Perfusion with isoproterenol lead to a significant increase in APD30 and APD90 (Figures 2A,C, respectively) and a significant decrease in APD50 (Figure 2B). Interestingly, canine endocardial myocytes treated with isoproterenol exhibit lengthening of
APD90 (Szentandrássy et al., 2012; Sala et al., 2018), similar to what we observed for the Goldfish. Unlike mammals, many fish species lack the slow component of the delay rectifier current (IKs), the main current system mediating repolarization effects of adrenergic stimulation on cardiac AP duration (Vornanen, 2017). The absence of this repolarizing current could explain the counterintuitive prolongation of APD30 and APD90 in the presence of an adrenergic stimulus. However, the role of $\mathrm{I}_{\mathrm{Ks}}$ in response to adrenergic stimulation is not yet elucidated in the Goldfish heart, and further studies are necessary to corroborate this hypothesis.

Transmural electrocardiograms were recorded in the presence and absence of isoproterenol (Figure 3) to examine its effect on whole heart electrical activity. Indeed, isoproterenol perfusion not only altered the morphology of the electrocardiogram (Figure 3A) but also reaffirmed the positive chronotropic effect 


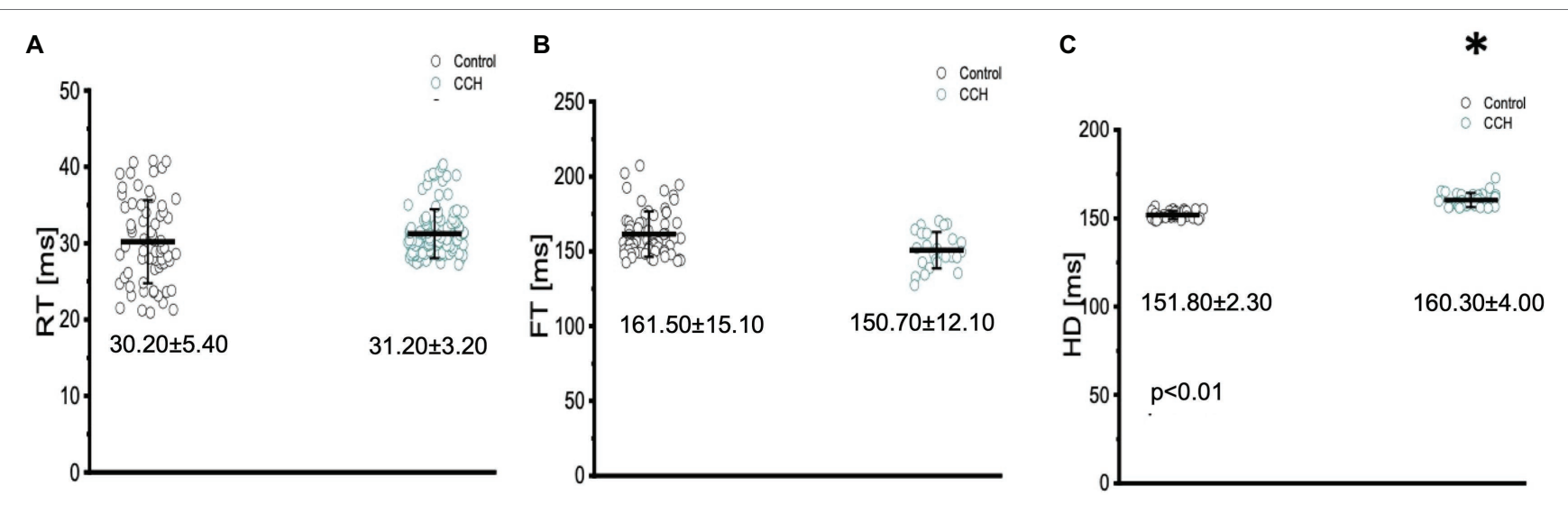

FIGURE 12 | The three kinetical properties of the $\mathrm{Ca}^{2+}$ transient, including the rise time (RT), fall time (FT), and half duration (HD) before (black) and after (green) perfusion with $5 \mu \mathrm{m}$ carbamylcholine. Administration of $5 \mu \mathrm{m}$ carbamylcholine did not significantly increase the rise time of the Ca ${ }^{2+}$ transient from $30.20 \pm 5.40 \mathrm{~ms}$ to $31.20 \pm 3.20 \mathrm{~ms}(p>0.01, n=69$ for the control, $n=85$ for $\mathrm{CCH}, N=8 ; \mathbf{A})$ or decrease the fall time $(\mathrm{FT})$ from $161.50 \pm 15.10 \mathrm{~ms}$ to $150.70 \pm 12.10 \mathrm{~ms}(p>0.01, n=59$ for the control, $n=27$ for $\mathrm{CCH}, N=8$; B). However, the half duration of the $\mathrm{Ca}^{2+}$ transient significantly increased from $151.80 \pm 2.30 \mathrm{~ms}$ to $160.30 \pm 4.00 \mathrm{~ms}(p<0.01$, $n=29$ for the control, $n=31$ for $\mathrm{CCH}, N=8$; C). *Denotes a significant difference between the two distributions. The data are presented as multiple measurements ( $n$; dot cloud) recorded for different measurements $(n)$ on different hearts $(N)$ with the mean \pm SEM (solid lines).

(Figures 3B,C) of isoproterenol presented in Figure 1. The positive chronotropic effect could be due to an increased slope of diastolic depolarization, as many other mammals exhibit the same pattern in response to adrenergic stimulation (Randall et al., 2020).

Isoproterenol's significant effect on whole heart excitability (Figure 4) not only reaffirms the presence of a positive chronotropic effect, but also suggests the instigation of a positive dromotropic effect. Because the QRS complex represents ventricular depolarization, its duration indirectly measures intraventricular impulse conduction. Thus, the positive dromotropic effect induced by isoproterenol can best be observed in Figure $\mathbf{4 A}$, where administration of the catecholamine significantly reduced the duration of the QRS complex and increased the rate of intraventricular impulse conduction. Furthermore, isoproterenol significantly increased the duration of the $\mathrm{T}$ wave, and significantly prolonged the duration of the J wave (Figures $4 \mathrm{~B}, \mathrm{C}$ ). An increased J wave duration is consistent with the prolongation of the APD30 in the presence of $100 \mathrm{~nm}$ of isoproterenol (Figure 2A). These modifications observed in the electrocardiogram further solidify the hypothesis that Goldfish exhibit sympathetic regulation, as perfusion with a catecholamine significantly modified cardiac excitability. The cardiac AP alters the mechanical function of vertebrate hearts by increasing intracellular free $\mathrm{Ca}^{2+}$ concentration, ultimately inducing cardiac contractions (Coraboeuf, 1978; Randall et al., 2020). In the Goldfish heart, $\mathrm{Ca}^{2+}$ influx through the LTCCs is the most likely trigger of $\mathrm{Ca}^{2+}$ release from the sarcoplasmic reticulum (Bazmi and Escobar, 2020), which ultimately augments cardiac contractile properties. Therefore, modifications in $\mathrm{Ca}^{2+}$ handling dynamics are essential for understanding how cardiac excitability alters cardiac contractility.

Epicardial $\mathrm{Ca}^{2+}$ transient recordings from the Goldfish ventricle show administration of isoproterenol altered the morphology of the $\mathrm{Ca}^{2+}$ transient and significantly increased the normalized amplitude of the $\mathrm{Ca}^{2+}$ transient (Figures $5 \mathbf{A}, \mathbf{B}$ ), a trend also observed in guinea pigs (Katra et al., 2004). The positive chronotropic effect (Figures 1C, 3C) in response to adrenergic stimulation could be explained by the alterations present in the $\mathrm{Ca}^{2+}$ transient dynamics followed by isoproterenol perfusion. A significant increase in the $\mathrm{Ca}^{2+}$ transient amplitude following adrenergic stimulation (Figure 5B) suggests isoproterenol increased the $\mathrm{Ca}^{2+}$ current, likely through the LTCC (Bazmi and Escobar, 2020). As previously discussed, adrenergic stimulation activates a cascade of events that phosphorylate numerous $\mathrm{Ca}^{2+}$ handling proteins, including PLN on serine 16 and threonine 17. Phosphorylation of PLN removes its inhibitory effect on the cardiac sarcoplasmic endoplasmic reticulum ATPase, thus increasing $\mathrm{Ca}^{2+}$ load into the sarcoplasmic reticulum. An increased $\mathrm{Ca}^{2+}$ transient amplitude increases the influx of positive charges into the myocardium and reduces the AP threshold; both of which increase the conduction velocity of the AP, resulting in a positive dromotropic effect. Furthermore, an increased $\mathrm{Ca}^{2+}$ current will increase the amount of $\mathrm{Ca}^{2+}$ in the sarcoplasmic reticulum and ultimately increase $\mathrm{Ca}^{2+}$ induced $\mathrm{Ca}^{2+}$ release. This would then increase the strength of contraction, resulting in the positive inotropic effect observed in Figure 5. To our knowledge, a positive inotropic effect in response to adrenergic stimulation has yet to be observed in the ventricle of any other fish species (Vornanen and Tuomennoro, 1999; Molina et al., 2007; Vornanen et al., 2010; Abramochkin and Vornanen, 2017). However, it is likely previous studies did not observe positive dromotropic effects considering many of them performed similar experiments on isolated cardiomyocytes and not at the intact heart level. Looking at changes in the kinetic properties of the Goldfish heart, it is likely isoproterenol also had a positive lusitropic effect. Although all three kinetical parameters of the Goldfish $\mathrm{Ca}^{2+}$ transient decreased 
following isoproterenol perfusion (Figures 6A-C), the lusitropic effect can be best observed in Figure 6B, as the fall time of the $\mathrm{Ca}^{2+}$ transient significantly decreased, suggesting isoproterenol increased the rate of myocardial relaxation during diastole.

\section{Muscarinic Stimulation Decreased Cardiac Excitability and Contractility}

As previously mentioned, an organism with an adrenergic drive could potentially also have a cholinergic drive, as they are the two antagonistic branches of the autonomic nervous system. Cholinergic control, however, is stronger than adrenergic control and has a negative chronotropic, dromotropic, inotropic, and lusitropic effect (Randall et al., 1968; Urbá-Holmgren et al., 1977; Laurent et al., 1983; Farrell, 1984; Axelsson et al., 1987). In the Goldfish model, perfusing the heart with $5 \mu \mathrm{m}$ carbamylcholine prolonged the AP (Figure 7A) and had a negative chronotropic effect (Figures 7B,C). The strong negative chronotropic effect induced by cholinergic stimulation could be mediated by an $\mathrm{ACh}$ activated potassium current $\left(\mathrm{IK}_{\mathrm{Ach}}\right)$; a major current found in fish atrial myocytes responsible for the repolarization of the membrane potential (Molina et al., 2007; Vornanen et al., 2010; Abramochkin and Vornanen, 2017). Furthermore, the activation of a muscarinic receptor will produce inhibition of the adenylyl cyclase reducing the levels of cAMP, preventing PKA-mediated phosphorylation. It is important to note, however, the levels of cAMP are finely regulated by PDEs, which contribute to the lowered cAMP concentrations. Nevertheless, lowered PKA levels result in a reduction in key phosphorylation sites, which ultimately decrease the slope of the diastolic depolarization and decrease heart rate. Furthermore, administration of carbamylcholine significantly prolonged all three kinetical parameters of the AP duration (Figures 8A-C). Considering previous research has shown the presence of $\mathrm{Ca}^{2+}$ dependent inactivation of the LTCC in Goldfish ventricular myocytes (Bazmi and Escobar, 2020), it is likely a decreased sarcolemmal $\mathrm{Ca}^{2+}$ influx mediated by carbamylcholine (Figure 11B) decelerated inactivation and prolonged the duration of the action potential.

In order to determine how the stimulation of cholinergic response modulated whole heart electrical activity, electrocardiograms were recorded in the presence and absence of carbamylcholine (Figure 9). Perfusion with carbamylcholine altered electrocardiogram morphology (Figure 9A) and reaffirmed the negative chronotropic effect (Figures 9B,C) presented in Figure 7B. Modification of whole heart excitability in response to muscarinic stimulation is presented in Figure 10. Interestingly, the duration of the QRS complex decreased in response to carbamylcholine administration, suggesting a slight positive dromotropic response, something typically observed in tachycardia. Currently, little is known about the depolarizing ventricular currents in the Goldfish which could provide further insight as to why cholinergic stimulation would reduce the duration of the QRS complex. Carbamylcholine perfusion also significantly increased the
$\mathrm{T}$ and $\mathrm{J}$ wave durations (Figures 10A-C); however, the increased $\mathrm{J}$ wave was expected as there was a corresponding increase in APD30 (Figure 8A).

The negative chronotropic effect induced by stimulation of the muscarinic receptors could also be explained by modifications of the $\mathrm{Ca}^{2+}$ transient. Administration of $5 \mu \mathrm{M}$ carbamylcholine modified $\mathrm{Ca}^{2+}$ transient morphology and significantly decreased the amplitude of the $\mathrm{Ca}^{2+}$ transient, suggesting stimulation of muscarinic receptors may have had a negative inotropic effect (Figures 11A,B). This is particularly interesting because previous studies conducted in isolated cardiac myocytes suggest muscarinic stimulation produced minor changes in cardiac chronotropic and inotropic properties in the fish heart (Laurent et al., 1983; Fritsche and Nilsson, 1990; Steele et al., 2009). This discrepancy, however, could be explained by the fact that other experiments were conducted in isolated myocytes, while our experiments were performed in the intact heart. As the heart is an electrically coupled organ, isolation of cardiac myocytes disrupts this electrical coupling, which may alter cardiac contractile properties.

A reduction in the $\mathrm{Ca}^{2+}$ current amplitude (Figure 11B) is likely to have reduced the slope of the diastolic depolarization and, as such, induced a negative chronotropic effect. As mentioned before, there are numerous mechanisms by which this slope may change. During cholinergic stimulation, PDEs and inhibition of adenylyl cyclase reduce cAMP levels which not only lower the activation of PKA, but also reduce stimulation of HCN channels. The current produced by these channels, $I_{f}$, typically increases the slope of the diastolic depolarization. However, in the presence of a cholinergic agonist, stimulation of If decreases, thus reducing the slope of the diastolic depolarization and ultimately reducing heart rate. Interestingly, HCN4 pacemaker channels have only been identified in the pacemaker region of the Goldfish and Zebrafish (Tessadori et al., 2012; Newton et al., 2014). Another possible mechanism by which muscarinic receptor stimulation induced a negative chronotropic response could be activation $\left(\mathrm{IK}_{\mathrm{Ach}}\right)$, although the contribution of this current is still poorly elucidated in fish ventricular myocytes (Molina et al., 2007; Vornanen et al., 2010; Abramochkin and Vornanen, 2017). Activation of $\mathrm{IK}_{\mathrm{ACh}}$ would induce hyperpolarization of the maximum diastolic potential, decreasing the heart rate. A decreased $\mathrm{Ca}^{2+}$ current and activation of $\mathrm{IK}_{\mathrm{ACh}}$ also lead to a negative dromotropic effect as a decreased $\mathrm{Ca}^{2+}$ current will decrease the influx of positive charges, increase the threshold of the AP, and decrease the mean diastolic potential; all of which reduce AP conduction velocity and induce a negative dromotropic effect.

Modifications presented in the kinetic properties of the Goldfish heart following carbamylcholine perfusion (Figure 12) suggest stimulation of the muscarinic receptor induced a minor negative lusitropic effect. While the half duration of the $\mathrm{Ca}^{2+}$ transient significantly increased in response to carbamylcholine perfusion (Figure 12C), the rise time and fall time were not significantly altered (Figures 12A,B). These results are interesting because the effect of carbamylcholine is in the opposite direction 
of what happens in mouse hearts and is very similar to larger mammals (Aguilar-Sanchez et al., 2019).

\section{CONCLUSION}

We conclude that the Goldfish heart is a very interesting model to study autonomic regulation due to its similarities with larger mammals. Although the Goldfish heart only has two chambers, its strikingly similar electrophysiological and autonomic characteristics make it a suitable model to study larger mammalian pathophysiology.

\section{DATA AVAILABILITY STATEMENT}

The raw data supporting the conclusions of this article will be made available by the authors, without undue reservation.

\section{REFERENCES}

Abramochkin, D. V., and Vornanen, M. (2017). Seasonal changes of cholinergic response in the atrium of Arctic navaga cod (Eleginus navaga). J. Comp. Physiol. B. 187, 329-338. doi: 10.1007/s00360-016-1032-y

Aguilar-Sanchez, Y., Fainstein, D., Mejia-Alvarez, R., and Escobar, A. L. (2017). Local field fluorescence microscopy: imaging cellular signals in intact hearts. J. Vis. Exp. 121:55202. doi: 10.3791/55202

Aguilar-Sanchez, Y., Rodriguez de Yurre, A., Argenziano, M., Escobar, A. L., and Ramos-Franco, J. (2019). Transmural autonomic regulation of cardiac contractility at the intact heart level. Front. Physiol. 10:773. doi: 10.3389/ fphys.2019.00773

Axelsson, M., Ehrenström, F., and Nilsson, S. (1987). Cholinergic and adrenergic influence on the teleost heart in vivo. Exp. Biol. 46, 179-186.

Bazmi, M., and Escobar, A. L. (2020). Excitation-contraction coupling in the goldfish (Carassius auratus) intact heart. Front. Physiol. 11:1103. doi: 10.3389/ fphys.2020.01103

Brum, G., Osterrieder, W., and Trautwein, W. (1984). Beta-adrenergic increase in the calcium conductance of cardiac myocytes studied with the patch clamp. Eur. J. Phys. 401, 111-118. doi: 10.1007/BF00583870

Cohn, J. N. (1989). Sympathetic nervous system activity and the heart. Am. J. Hypertens. 2, 353S-356S.

Collins, J. H., Kranias, E. G., Reeves, A. S., Bilezikjian, L. M., and Schwartz, A. (1981). Isolation of phospholamban and a second proteolipid component from canine cardiac sarcoplasmic reticulum. Biochem. Biophys. Res. Commun. 99, 796-803. doi: 10.1016/0006-291X(81)91235-3

Coraboeuf, E. (1978). Ionic basis of electrical activity in cardiac tissues. Am. J. Phys. Heart Circ. Phys. 234, H101-H116. doi: 10.1152/ajpheart.1978.234.2.H101

Escobar, A. L., Fernández-Gómez, R., Peter, J.-C., Mobini, R., Hoebeke, J., and Mijares, A. (2006). IgGs and Mabs against the $\beta 2$-adrenoreceptor block A-V conduction in mouse hearts: a possible role in the pathogenesis of ventricular arrhythmias. J. Mol. Cell. Cardiol. 40, 829-837. doi: 10.1016/j.yjmcc.2006.03.430

Escobar, A. L., Ribeiro-Costa, R., Villalba-Galea, C., Zoghbi, M. E., Pérez, C. G., and Mejía-Alvarez, R. (2004). Developmental changes of intracellular $\mathrm{Ca}^{2+}$ transients in beating rat hearts. Am. J. Phys. Heart Circ. Phys. 286, H971H978. doi: 10.1152/ajpheart.00308.2003

Evans, D. B. (1986). Modulation of cAMP: mechanism for positive inotropic action. J. Cardiovasc. Pharmacol. 8(Suppl. 9), S22-S29. doi: 10.1097/00005344198611001-00003

Farrell, A. P. (1984). A review of cardiac performance in the teleost heart: intrinsic and humoral regulation. Can. J. Zool. 62, 523-536. doi: 10.1139/ z84-079

\section{ETHICS STATEMENT}

The animal study was reviewed and approved by Association for Assessment and Accreditation of Laboratory Animal Care (2008-201).

\section{AUTHOR CONTRIBUTIONS}

$\mathrm{MB}$ and $\mathrm{AE}$ designed and performed the research, analyzed data, and wrote the paper. All authors contributed to the article and approved the submitted version.

\section{FUNDING}

The study was supported by NIH (R01 HL-084487 to AE) and NIH (1R01HL152296 to AE).
Ferreiro, M., Petrosky, A. D., and Escobar, A. L. (2012). Intracellular $\mathrm{Ca}^{2+}$ release underlies the development of phase 2 in mouse ventricular action potentials. Am. J. Phys. Heart Circ. Phys. 302, H1160-H1172. doi: 10.1152/ ajpheart.00524.2011

Fritsche, R., and Nilsson, S. (1990). Autonomic nervous control of blood pressure and heart rate during hypoxia in the cod, Gadus morhua. J. Comp. Physiol. B. 160, 287-292. doi: 10.1007/BF00302594

Harper, A. A., Newton, I. P., and Watt, P. W. (1995). The effect of temperature on spontaneous action potential discharge of the isolated sinus venosus from winter and summer plaice (Pleuronectes platessa). J. Exp. Biol. 198, 137-140. doi: 10.1242/jeb.198.1.137

Haverinen, J., and Vornanen, M. (2007). Temperature acclimation modifies sinoatrial pacemaker mechanism of the rainbow trout heart. Am. J. Phys Regul. Integr. Comp. Phys. 292, R1023-R1032. doi: 10.1152/ajpregu.00432. 2006

Hayes, J. S., and Mayer, S. E. (1981). Regulation of Guinea pig heart phosphorylase kinase by cAMP, protein kinase, and calcium. Am. J. Physiol. Endocrinol. Metab. 240, E340-E349. doi: 10.1152/ajpendo.1981.240.3. E340

Henning, R. J. (1992). Vagal stimulation during muscarinic and $\beta$-adrenergic blockade increases atrial contractility and heart rate. J. Auton. Nerv. Syst. 40, 121-129. doi: 10.1016/0165-1838(92)90023-A

Hildebrandt, J. D., Sekura, R. D., Codina, J., Iyengar, R., Manclark, C. R., and Birnbaumer, L. (1983). Stimulation and inhibition of adenylyl cyclases mediated by distinct regulatory proteins. Nature 302, 706-709. doi: $10.1038 / 302706 \mathrm{a} 0$

Katra, R. P., Pruvot, E., and Laurita, K. R. (2004). Intracellular calcium handling heterogeneities in intact Guinea pig hearts. Am. J. Phys. Heart Circ. Phys. 286, H648-H656. doi: 10.1152/ajpheart.00374.2003

Katz, A. M. (1967). Regulation of cardiac muscle contractility. J. Gen. Physiol. 50, 185-196. doi: 10.1085/jgp.50.6.185

Keith, A., and Mackenzie, I. (1910). Recent researches on the anatomy of the heart. Lancet 175, 101-103. doi: 10.1016/S0140-6736(01)74711-3

Kornyeyev, D., Reyes, M., and Escobar, A. L. (2010). Luminal $\mathrm{Ca}^{2+}$ content regulates intracellular $\mathrm{Ca}^{2+}$ release in subepicardial myocytes of intact beating mouse hearts: effect of exogenous buffers. Am. J. Phys. Heart Circ. Phys. 298, H2138-H2153. doi: 10.1152/ajpheart.00885.2009

Krebs, E. G. (1972). Protein kinases. Curr. Top. Cell. Regul. 5, 99-133. doi: 10.1016/B978-0-12-152805-8.50010-1

Laurent, P., Holmgren, S., and Nilsson, S. (1983). Nervous and humoral control of the fish heart: structure and function. Comp. Biochem. Physiol. A Physiol. 76, 525-542. doi: 10.1016/0300-9629(83)90455-3 
Lee, W. C., and Shideman, F. E. (1959). Role of myocardial Catecholamines in cardiac contractility. Science 129, 967-968. doi: 10.1126/science.129. 3354.967

Lindemann, J. P., and Watanabe, A. M. (1985). Muscarinic cholinergic inhibition of beta-adrenergic stimulation of phospholamban phosphorylation and $\mathrm{Ca}^{2+}$ transport in Guinea pig ventricles. J. Biol. Chem. 260, 13122-13129. doi: 10.1016/S0021-9258(17)38847-6

López Alarcón, M. M., Rodríguez de Yurre, A., Felice, J. I., Medei, E., and Escobar, A. L. (2019). Phase 1 repolarization rate defines $\mathrm{Ca}^{2+}$ dynamics and contractility on intact mouse hearts. J. Gen. Physiol. 151, 771-785. doi: 10.1085/jgp.201812269

Marks, A. R. (2013). Calcium cycling proteins and heart failure: mechanisms and therapeutics. J. Clin. Investig. 123, 46-52. doi: 10.1172/JCI62834

Mattiazzi, A., Argenziano, M., Aguilar-Sanchez, Y., Mazzocchi, G., and Escobar, A. L. (2015). Ca2+ Sparks and $\mathrm{Ca} 2+$ waves are the subcellular events underlying $\mathrm{Ca} 2+$ overload during ischemia and reperfusion in perfused intact hearts. J. Mol. Cell. Cardiol. 79, 69-78. doi: 10.1016/j.yjmcc.2014.10.011

Mejía-Alvarez, R., Manno, C., Villalba-Galea, C. A., del Valle Fernández, L., Costa, R., Fill, M., et al. (2003). Pulsed local-field fluorescence microscopy: A new approach for measuring cellular signals in the beating heart. Pflugers Arch. 445, 747-758. doi: 10.1007/s00424-002-0963-1

Mersereau, E. J., Poitra, S. L., Espinoza, A., Crossley, D. A., and Darland, T. (2015). The effects of cocaine on heart rate and electrocardiogram in zebrafish (Danio rerio). Comp. Bioche. Physiol. C Toxicol. Pharmacol. 172-173, 1-6. doi: 10.1016/j.cbpc.2015.03.007

Molina, C. E., Gesser, H., Llach, A., Tort, L., and Hove-Madsen, L. (2007). Modulation of membrane potential by an acetylcholine-activated potassium current in trout atrial myocytes. Am. J. Phys. Regul. Integr. Comp. Phys. 292, R388-R395. doi: 10.1152/ajpregu.00499.2005

Nakamura, T., Lozano, P. R., Ikeda, Y., Iwanaga, Y., Hinek, A., Minamisawa, S., et al. (2002). Fibulin-5/DANCE is essential for elastogenesis in vivo. Nature 415, 171-175. doi: 10.1038/415171a

Newton, C. M., Stoyek, M. R., Croll, R. P., and Smith, F. M. (2014). Regional innervation of the heart in the goldfish, Carassius auratus: a confocal microscopy study: innervation of the goldfish heart. J. Comp. Neurol. 522, 456-478. doi: 10.1002/cne.23421

O'Hara, T., and Rudy, Y. (2012). Quantitative comparison of cardiac ventricular myocyte electrophysiology and response to drugs in human and nonhuman species. Am. J. Phys. Heart Circ. Phys. 302, H1023-H1030. doi: 10.1152/ ajpheart.00785.2011

Osterrieder, W., Brum, G., Hescheler, J., Trautwein, W., Flockerzi, V., and Hofmann, F. (1982). Injection of subunits of cyclic AMP-dependent protein kinase into cardiac myocytes modulates Ca2+ current. Nature 298, 576-578. doi: 10.1038/298576a0

Randall, W. C., Randall, D. C., and Ardell, J. L. (2020). "Autonomic regulation of myocardial contractility," in Reflex Control of the Circulation. 1st Edn. eds. I. H. Zucker and J. P. Gilmore (United Kingdom: Taylor and Francis), 67-103.

Randall, W., Wechsler, J., Pace, J., and Szentivanyi, M. (1968). Alterations in myocardial contractility during stimulation of the cardiac nerves. Am. J. Physiol. 214, 1205-1212. doi: 10.1152/ajplegacy.1968.214.5.1205

Saito, T. (1973). Effects of vagal stimulation on the pacemaker action potentials of carp heart. Comp. Biochem. Physiol. A Physiol. 44, 191-199. doi: 10.1016/0300-9629(73)90381-2

Sala, L., Hegyi, B., Bartolucci, C., Altomare, C., Rocchetti, M., Váczi, K., et al. (2018). Action potential contour contributes to species differences in repolarization response to $\beta$-adrenergic stimulation. Europace 20, 1543-1552. doi: 10.1093/europace/eux236

Sandblom, E., and Axelsson, M. (2011). Autonomic control of circulation in fish: A comparative view. Auton. Neurosci. 165, 127-139. doi: 10.1016/j. autneu.2011.08.006

Steele, S. L., Lo, K. H. A., Li, V. W. T., Cheng, S. H., Ekker, M., and Perry, S. F. (2009). Loss of $M_{2}$ muscarinic receptor function inhibits development of hypoxic bradycardia and alters cardiac $\beta$-adrenergic sensitivity in larval zebrafish (Danio rerio). Am. J. Phys. Regul. Integr. Comp. Phys. 297, R412R420. doi: 10.1152/ajpregu.00036.2009

Suko, J., Maurer-Fogy, I., Plank, B., Bertel, O., Wyskovsky, W., Hohenegger, M., et al. (1993). Phosphorylation of serine 2843 in ryanodine receptor-calcium release channel of skeletal muscle by cAMP-, cGMP- and CaM-dependent protein kinase. Biochim. Biophys. Acta 1175, 193-206. doi: 10.1016/01674889(93)90023-I

Szentandrássy, N., Farkas, V., Bárándi, L., Hegyi, B., Ruzsnavszky, F., Horváth, B., et al. (2012). Role of action potential configuration and the contribution of $\mathrm{Ca}^{2+}$ and $\mathrm{K}^{+}$currents to isoprenaline-induced changes in canine ventricular cells: isoprenaline in canine heart. Br. J. Pharmacol. 167, 599-611. doi: 10.1111/j.1476-5381.2012.02015.x

Tessadori, F., van Weerd, J. H., Burkhard, S. B., Verkerk, A. O., de Pater, E., Boukens, B. J., et al. (2012). Identification and functional characterization of cardiac pacemaker cells in Zebrafish. PLoS One 7:e47644. doi: 10.1371/ journal.pone.0047644

Tsai, C.-T., Wu, C.-K., Chiang, F.-T., Tseng, C.-D., Lee, J.-K., Yu, C.-C., et al (2011). In-vitro recording of adult zebrafish heart electrocardiogram-A platform for pharmacological testing. Clin. Chim. Acta 412, 1963-1967. doi: 10.1016/j.cca.2011.07.002

Urbá-Holmgren, R., González, R. M., and Holmgren, B. (1977). Is yawning a cholinergic response? Nature 267, 261-262. doi: 10.1038/267261a0

Valdivia, H. H., Kaplan, J. H., Ellis-Davies, G. C., and Lederer, W. J. (1995). Rapid adaptation of cardiac ryanodine receptors: modulation by $\mathrm{Mg}^{2+}$ and phosphorylation. Science 267, 1997-2000. doi: 10.1126/science.7701323

Valverde, C. A., Kornyeyev, D., Ferreiro, M., Petrosky, A. D., Mattiazzi, A., and Escobar, A. L. (2010). Transient Ca2+ depletion of the sarcoplasmic reticulum at the onset of reperfusion. Cardiovasc. Res. 85, 671-680. doi: $10.1093 / \mathrm{cvr} / \mathrm{cvp} 371$

Valverde, C. A., Mundiña-Weilenmann, C., Reyes, M., Kranias, E. G., Escobar, A. L., and Mattiazzi, A. (2006). Phospholamban phosphorylation sites enhance the recovery of intracellular $\mathrm{Ca}^{2+}$ after perfusion arrest in isolated, perfused mouse heart. Cardiovasc. Res. 70, 335-345. doi: 10.1016/j. cardiores.2006.01.018

Vornanen, M. (2017). "Electrical excitability of the fish heart and its autonomic regulation," in Fish Physiology. Vol. 36. eds. A. K. Gamperl, T. E. Gillis, A. P. Farrell and C. J. Brauner (New York: Elsevier), 99-153.

Vornanen, M., Hälinen, M., and Haverinen, J. (2010). Sinoatrial tissue of crucian carp heart has only negative contractile responses to autonomic agonists. BMC Physiol. 10:10. doi: 10.1186/1472-6793-10-10

Vornanen, M., and Tuomennoro, J. (1999). Effects of acute anoxia on heart function in crucian carp: importance of cholinergic and purinergic control. Am. J. Phys. 277, R465-R475. doi: 10.1152/ajpregu.1999.277.2.R465

Watanabe, A. M., and Lindemann, J. P. (1984). "Mechanisms of adrenergic and cholinergic regulation of myocardial contractility," in Physiology and Pathophysiology of the Heart. Vol. 34. ed. N. Sperelakis (United States: Springer), 377-404.

Weilenmann, C. M., Vittone, L., Cingolani, G., and Mattiazzi, A. (1987). Dissociation between contraction and relaxation: the possible role of phospholamban phosphorylation. Basic Res. Cardiol. 82, 507-516. doi: 10.1007/ BF01907220

Xing, N., Ji, L., Song, J., Ma, J., Li, S., Ren, Z., et al. (2017). Cadmium stress assessment based on the electrocardiogram characteristics of zebra fish (Danio rerio): QRS complex could play an important role. Aquat. Toxicol. 191, 236-244. doi: 10.1016/j.aquatox.2017.08.015

Conflict of Interest: The authors declare the research was conducted in the absence of any commercial or financial relationships that could be construed as a potential conflict of interest.

Publisher's Note: All claims expressed in this article are solely those of the authors and do not necessarily represent those of their affiliated organizations, or those of the publisher, the editors and the reviewers. Any product that may be evaluated in this article, or claim that may be made by its manufacturer, is not guaranteed or endorsed by the publisher.

Copyright (C) 2022 Bazmi and Escobar. This is an open-access article distributed under the terms of the Creative Commons Attribution License (CC BY). The use, distribution or reproduction in other forums is permitted, provided the original author(s) and the copyright owner(s) are credited and that the original publication in this journal is cited, in accordance with accepted academic practice. No use, distribution or reproduction is permitted which does not comply with these terms. 